\title{
Elastic fiber assembly is disrupted by excessive accumulation of chondroitin sulfate in the human dermal fibrotic disease, keloid
}

\section{AUTHOR(S):}

Ikeda, Mika; Naitoh, Motoko; Kubota, Hiroshi; Ishiko, Toshihiro; Yoshikawa, Katsuhiro; Yamawaki, Satoko; Kurokawa, Masako; ... Nakamura, Tomiyuki; Nagata, Kazuhiro; Suzuki, Shigehiko

\section{CITATION:}

Ikeda, Mika ...[et al]. Elastic fiber assembly is disrupted by excessive accumulation of chondroitin sulfate in the human dermal fibrotic disease, keloid. Biochemical and Biophysical Research Communications 2009, 390(4): 1221-1228

\section{ISSUE DATE:}

2009-12-25

URL:

http://hdl.handle.net/2433/88959

\section{RIGHT:}

c 2009 Elsevier Inc. All rights reserved.; This is not the published version. Please cite only the published version.; この論文は出版社版でありませ ん。引用の際には出版社版をご確認ご利用ください。 


\section{Elastic fiber assembly is disrupted by excessive accumulation of chondroitin sulfate in the human dermal fibrotic disease, keloid}

Mika Ikeda $^{\mathrm{a}}$, Motoko Naitoh ${ }^{\mathrm{a}, *}$, Hiroshi Kubota ${ }^{\mathrm{b}}$, Toshihiro Ishiko ${ }^{\mathrm{a}}$, Katsuhiro Yoshikawa ${ }^{a}$, Satoko Yamawaki ${ }^{a}$, Masato Kurokawa ${ }^{c}$, Atsushi Utani $^{\mathrm{d}}$, Tomoyuki Nakamura ${ }^{\mathrm{e}}$, Kazuhiro Nagata ${ }^{\mathrm{b}}$ and Shigehiko Suzuki ${ }^{\mathrm{a}}$

${ }^{a}$ Department of Plastic and Reconstructive Surgery, Graduate School of Medicine, Kyoto University, Kyoto 606-8507, Japan;

${ }^{\mathrm{b}}$ Department of Molecular and Cellular Biology, Institute for Frontier

Medical Science, Kyoto University, Kyoto 606-8397, Japan;

${ }^{\mathrm{c}}$ Department of Plastic and Reconstructive Surgery, Nagahama Red Coss Hospital, Shiga 526-8585, Japan.

${ }^{\mathrm{d}}$ Department of Dermatology, Graduate School of Medicine, Kyoto University, Kyoto 606-8507, Japan;

${ }^{\mathrm{e}}$ Department of Pharmacology, Kansai Medical University, Osaka 570-8506, Japan.

* Corresponding author: Motoko Naitoh, Department of Plastic and Reconstructive Surgery, Graduate School of Medicine, Kyoto University, Kyoto 606-8507, Japan. Tel. 81-75-751-3613. Fax. 81-75-751-4340.

E-mail: mnaitoh@kuhp.kyoto-u.ac.jp. 
Abstract

Keloid is a fibrotic disease characterized by abnormal accumulation of extracellular matrix in the dermis. The keloid matrix contains excess collagen and glycosaminoglycans (GAGs), but lacks elastic fiber.

However, the roles of these matrix components in the pathogenesis of keloid are largely unknown. Here, we show that elastin and DANCE (also known as fibulin-5), a protein required for elastic fiber formation, are not deposited in the extracellular matrix of keloids, due to excess accumulation of chondoitin sulfate (CS), although the expression of elastin and DANCE is not affected. Amount of CS accumulated in the keloid legion was 6.9-fold higher than in normal skin. Fibrillin-1, a scaffold protein for elastic fiber assembly, was abnormally distributed in the keloid matrix. Addition of purified CS to keloid fibroblast culture resulted in abnormal deposition of fibrillin-1, concomitant with significantly decreased accumulation of elastin and DANCE in the extracellular matrix. We propose that CS plays a crucial role in the development of keloid lesions through inhibition of elastic fiber assembly.

Key words: keloid, wound healing, elastic fibers, glycosaminoglycan, chondroitin sulfate, DANCE/fibulin-5 
Introduction

Keloids are benign dermal tumors that appear as raised, red, itchy, painful lesions that develop during the wound-healing process [1]. Keloid lesions expand beyond the boundaries of the initial injury site through the rapid proliferation of fibroblast-like cells. Keloid lesions contain excess amounts of extracellular matrix [2-4]. Collagen types I and VI are the major components of the excessive matrix [3,4], and collagen type III is also strongly upregulated in the keloid lesions [4].

Recently, we demonstrated that glycosaminoglycans (GAGs), which are an important component of human skin, are abundant in the keloid matrix [2]. GAGs can be divided into four classes: (i) chondroitin sulfate (CS) (ii) keratan sulfate (KS), (iii) heparan sulfate (HS) / heparin, and (iv) hyaluronan (HA). CS is further divided into five subtypes: CSA, CSB (also known as dermatan sulfate, DS), CSC, CSD and CSE. GAGs are linear polysaccharides composed of repeating disaccharide units consisting of an amino sugar, either N-acetyl-D-glucosamine (D-GlcNAc) or N-acetyl-D-galactosamine (D-GalNAc), and an uronic acid, either D-glucuronic (D-GlcA) or L-iduronic acid (L-IdoA), with the exception of KS. In KS, a galactose residue is present in place of the uronic acid [5]. Although the basic sugar backbone is similar among GAGs, subsequent modifications including sulfation, deacetylation and epimerization distinguish the individual GAG members and are critical for their specific 
activities [5]. CS, KS and HS, but not HA, are covalently attached to protein cores, creating proteoglycans (PGs). Although Swann et al. analyzed the differences in PGs between normal skin and scar tissues, including keloids, only one sample of normal skin and of keloid tissue was examined [6]. Thus, the role of PGs in keloid pathogenesis is largely unknown.

Elastic fibers are one of the major components of human skin. Elastic fibers are lost or markedly reduced in keloid lesions [7, 8], although a detailed analysis of elastic fiber components in keloids has not been conducted. Elastic fibers are formed from two distinct components: an amorphous core of cross-linked elastin and a peripheral mantle of microfibrils [9]. In the process of elastic fiber formation, elastin precursors (tropoelastin) are deposited onto microfibrils, aligned, and cross-linked to form mature elastin [10]. The molecular mechanism of this process remains largely unknown. Mice lacking both fibrillin-1 and -2, major components of microfibrils, were recently reported to be deficient in elastic fiber formation [11], suggesting that microfibrils are required for normal assembly of elastin. Fibrillin is thought to act as a scaffold for the deposition of tropoelastin onto microfibrils. DANCE (also known as fibulin-5) is also required for elastic fiber assembly, as revealed in DANCE-deficient mice [12, 13].

Here, we analyzed elastic fiber components and glycosaminoglycans in keloid lesions, and found that deposition of elastin and DANCE on 
microfibrils is abrogated and that distribution of fibrillin-1 is abnormal in keloid lesions, although these molecules are normally expressed. CS is abundant in keloid lesions, and addition of CS to fibroblast culture caused inhibition of elastin and DANCE deposition due to aberrant fibrillin microfibrils. Thus, CS appears to play an important role in diminished elastic fiber formation in keloids.

Materials and Methods

\section{Tissue specimens}

Eighteen patients with keloid (aged 11-75 years) and seven unrelated patients (aged 1-69 years) undergoing surgical treatment were enrolled in this study (Supplementary Table 1). With approval from Institutional Reviewing Board in Kyoto University faculty of medicine in accordance with ethical standards as formulated in the Helsinki Declaration, informed consent was obtained from all of the patients. Keloid diagnosis was performed on the basis of the clinical appearance, history and anatomical location. All lesions analyzed in this study satisfied the histological criteria for keloids by hematoxylin/eosin (HE) and Elastica van Gieson staining.

\section{Histological and immunohistochemical studies}

Tissue samples were fixed in $4 \%$ paraformaldehyde at $4^{\circ} \mathrm{C}$, and paraffin 
sections $(6 \mu \mathrm{m})$ were prepared. Deparaffinized sections were stained with $\mathrm{HE}$ and Elastica van Gieson. Alcian Blue staining was performed at $\mathrm{pH}$ 2.5, after an incubation with hyaluronidase (Seikagaku Corp., Tokyo, Japan) at $60{ }^{\circ} \mathrm{C}$ for $2 \mathrm{~h}$, chondroitinase-ABC (Seikagaku Corp.) at $37^{\circ} \mathrm{C}$ for $2 \mathrm{~h}$, or no enzymatic treatment. For immunological staining, cryosections $(10 \mu \mathrm{m})$ were prepared and fixed in $4 \%$ paraformaldehyde. Sections were incubated with antibodies against human elastin (1:200, PR533, EPC, Missouri, USA), human DANCE (1:200, 10A) [14], or human fibrillin-1 (1:400, PR217, EPC) for $60 \mathrm{~min}$ at room temperature. Sections were then incubated with Alexa 488-conjugated anti-mouse IgG or Alexa 546-conjugated anti-rabbit IgG (Invitrogen, California, USA). Sections were counterstained with Hoechst 33258 for nuclear staining, and images were obtained using a C1si confocal microscope (Nikon, Tokyo, Japan).

\section{Cell culture}

Tissues were cut into $1 \sim 2 \mathrm{~mm}^{3}$ pieces, placed into plastic tissue culture dishes, and cultured in Dulbecco's modified Eagle's medium supplemented with $10 \%$ fetal calf serum (Invitrogen). Cells were propagated at $37^{\circ} \mathrm{C}$, and semiconfluent cultures of fibroblasts were passaged by trypsinization up to seven times prior to analysis.

Elastic fiber formation by cultured keloid fibroblasts 
Keloid fibroblasts $\left(1 \times 10^{4}\right.$ cells $)$ were seeded onto a cover glass and cultured in DMEM/F12 (Invitrogen) supplemented with 10\% fetal calf serum in the presence or absence of CSA, CSB, CSC and HA (400 $\mu \mathrm{g} / \mathrm{ml}$ each or combinations, Seikagaku Corp.). After culture for 9 days, fibroblast cultures were fixed in $100 \%$ methanol at $-20^{\circ} \mathrm{C}$, and analyzed by immunostaining for elastin, DANCE and fibrillin-1. Evaluation of the effects of GAGs on elastogenesis was conducted according to previously described methods $[14,15,16]$

$R T-P C R$

Total RNA was isolated from normal skin and keloid tissue samples using the Trizol Reagent (Invitrogen) and RNeasy Mini Kits (Qiagen, Hilden, Germany). First-strand cDNA was synthesized from $1 \mu \mathrm{g}$ total RNA by reverse transcription at $42^{\circ} \mathrm{C}$ for 60 min using the Advantage RT for PCR kit (BD Biosciences, California, USA). Specific cDNA fragments were amplified using Blend Taq-plus (TOYOBO, Osaka, Japan) with the following primers: tropoelastin, AAGCAGCAGCAAAGTTCG and ACCTGGGACAACTGGAATCC; fibrillin-1, GTGAGATCAA CATCAATGGAGC and TTACACACTCCTGGGAACACTTC; fibulin-1, GATGTCCTCCTGGAGGCCTGCTGTG and TTGGGTC GGCAGCGGAAGGATCCCAG; DANCE, CGGCACATACTTCTG CTCCT and TCAGAATGGGTACTGCGACA; EMILIN-1, ATTA TGACCAGAGACAGGC and CCGAGTGCGCCAGCTGCCCC; MAGP-1, 
ATGAGAGCTGCCTACCTCTTC and CTAGCAGCTC

CCACAGCTCCT; GAPDH, TGGTATCGTGGAAGGACTCATGAC and ATGCCAGTGAGCTTCCCGTTCAGC. PCR reactions were conducted for 30 cycles for DANCE, MAGP-1, GAPDH, and 35 cycles for tropoelastin, fibrillin-1, fibulin-1 and EMILIN-1, where one PCR cycle consisted of denaturation at $94^{\circ} \mathrm{C}$ for $30 \mathrm{sec}$, annealing at $58^{\circ} \mathrm{C}$ for $30 \mathrm{sec}$, and extension at $72^{\circ} \mathrm{C}$ for $1 \mathrm{~min}$. PCR products were analyzed by agarose gel electrophoresis followed by ethidium bromide staining.

\section{High-performance liquid chromatography (HPLC) assays}

Tissues samples were frozen in liquid nitrogen immediately after collection and stored at $-80^{\circ} \mathrm{C}$ until analysis. After freeze-drying, samples were incubated with 2.5\% Actinase E (Kaken Pharmaceutical Corp., Ltd., Tokyo, Japan) at $55^{\circ} \mathrm{C}$ for $24 \mathrm{~h}$. After freeze-thawing, samples were centrifuged at 3,000 rpm for $10 \mathrm{~min}$ and supernatant were recovered. Measurement of CSA/C and CSB was performed according to the method of Shinmei et al. [17] with minor modifications. One aliquot of the supernatant was treated with $250 \mathrm{mU}$ of Chondroitinase ABC (Seikagaku Corp.) and $25 \mathrm{mU}$ of Chondroitinase AC-II (Seikagaku Corp.) in $20 \mathrm{mM}$ Tris- $\mathrm{HCl}$ buffer ( $\mathrm{pH} \mathrm{8).} \mathrm{Another} \mathrm{aliquot} \mathrm{of} \mathrm{the} \mathrm{supernatant} \mathrm{was} \mathrm{digested}$ by $250 \mathrm{mU}$ of Chondroitinase AC-II in $20 \mathrm{mM}$ sodium acetate buffer (pH 6). In both cases, samples were incubated at $37^{\circ} \mathrm{C}$ for $2 \mathrm{~h}$ and clarified by ultrafiltration with a Nanosep filter (molecular size cut-off of 10,000; 
PALL Corp., New York, USA). The ultrafiltrate was analyzed with modifications for the determination of each isomer as follows. The $\Delta \mathrm{di}-4 \mathrm{~S}$ value obtained from the digest of Chondroitinase ACII, which can act on $\mathrm{CSA} / \mathrm{C}$ but not on CSB, was used to determine the $\Delta$ diCS-4S levels, and the level of $\Delta$ diDS-4S was calculated by subtraction of the $\Delta$ di- $4 \mathrm{~S}$ value obtained from the Chondroitinase ACII digestion from that obtained from the Chondroitinase $\mathrm{ABC}$ plus Chondroitinase ACII digestion, which cleaves both CSA/C and CSB. The concentration of KS was determined according to the method of Shinmei et al. [17] and Yamada et al. [18] with minor modifications. Supernatants were treated with $1 \mathrm{mU}$ of Keratanase II (Seikagaku Corp.) in $20 \mathrm{mM}$ sodium acetate buffer (pH 6) at $37^{\circ} \mathrm{C}$ for 3 h. The samples were then clarified by ultrafiltration, and the filtrate, which contains the saturated disaccharides B-galactosyl-(1-4)-6-O-sulfo-N-acetylglucosamine (M-KS) and B-6-O-sulfo-galactosyl-(1-4)-6-O-sulfo-N-acetylglucosamine (D-KS), was analyzed by HPLC. The concentration of HA was analyzed according to the method of Takazono et al. [19] and Shinmei et al. [17] with minor modifications. Supernatant was treated with 2.5 TRU of Streptomyces hyalurolyticus hyaluronate lyase (Seikagaku Corp.) in $12.5 \mathrm{mM}$ sodium acetate buffer ( $\mathrm{pH}$ 6) at $37^{\circ} \mathrm{C}$ for $24 \mathrm{~h}$. Samples were clarified by ultrafiltration and analyzed by HPLC. 
Results

Deposition of elastin and DANCE is strongly reduced and distribution of fibrillin-1 is aberrant in keloid tissues

Keloids are known to lack elastic fibers [7, 8]. However, little is known of the detailed mechanisms mediating these changes. We first examined the distribution of elastin, fibrillin-1 and DANCE in keloid lesions by immunostaining tissue sections. Elastin stained very weakly in keloid lesions relative to normal skin (Fig. 1A). Reduced deposition of DANCE, a protein required for elastic fiber formation, was also detected in keloid tissues (Fig. 1B). The fibrillin-1 distribution was abnormal in keloid lesions. Although fibrillin-1 stained as fine fibers in normal skin, this protein distributed in thick and irregular bundles in keloid tissue. In addtion, we confirmed that elastic fibers are absent in keloid lesions by Elastica van Gieson staining (Fig. 1C). These observations suggest that the lack of elastic fibers in keloid lesions is due to a deficiency in DANCE and elastin depositin in the keloid matrix, and that the abnormal distribution of fibrillin-1 may also contribute to the absence of elastic fibers in keloid lesions.

Gene expression of proteins required for elastic fibers is normal in keloid lesions

To analyze the mechanisms mediating the strongly reduced levels of 
elastin and DANCE in keloid lesions, we examined mRNA expression of elastin, DANCE, fibrillin-1, fibrillin-2, and other elastic fiber components including fibulin-1 [20], EMILIN-1 [21], and MAGP-1 [22] by RT-PCR. As shown in Fig. 1D, levels of fibrillin-1, fibrillin-2 and MAGP-1 are upregulated in keloids, but mRNA levels of the other components were similar to those expressed in normal skin. The high levels of fibrillin-1, fibrillin-2, and MAGP-1 expression may play a role in the abnormal distribution of fibrillin-1 in keloids (Fig. 1B). These results suggest that the lack of elastic fibers in keloids is not due to changes in gene expression, but may be due to defective assembly process of the fiber components.

Keloid lesions contain high amounts of GAGs, particularly CS

We reported previously that keloid lesions show metachromasia, indicating an excess accumulation of GAGs including CS and HA [2]. Among GAG family members, CS is reported to impair elastogenesis in vascular smooth muscle cells in several cardiovascular diseases and in fibroblasts in congenital diseases [15, 23]. To analyze variations in GAGs accumulated in keloid lesions, we first performed Alcian Blue staining after digestions with GAG subtype-specific enzymes. In the absence of enzymatic treatment, keloid lesions were strongly stained by Alcian Blue, whereas normal skin was only weakly stained (Fig. 2A-a, b). After digestion by chondroitinase $\mathrm{ABC}$, which selectively reacts with $\mathrm{CS}$, the 
staining was greatly reduced in keloid samples (Fig. 2A-c). After hyaluronidase digestion, the staining in keloid samples also decreased, although the effect was less pronounced compared with the chondroitinase treatment (Fig. 2A-d). These data suggest that CS and HA accumulate to abnormally high levels in keloid lesions. To determine the content of GAG family members in keloid lesions, we quantified amounts of CSA/C, CSB, HA, and KS using an HPLC system (Table 1). The major GAGs in normal skin are HA and CSB (Fig. 2B, C), as reported previously [24]. Levels of CS, HA and KS were 6.9-fold, 1.7-fold and 3.0-fold higher, respectively, in keloids than in normal skin (Fig. 2B). CSB was the most abundant GAG in keloid tissues, and levels of CSA/C and CSB were 12.1-fold and 5.1-fold increased in keloids relative to normal skin, respectively (Fig. 2C). These results indicate that CS is extremely abundant GAG in keloid lesions.

\section{CS inhibits elastic fiber formation by cultured keloid fibroblasts}

As CS has been reported to inhibit elastogenesis in several pathological conditions $[15,23]$, we hypothesized that loss of elastic fibers in keloids may be caused by excess accumulation of CS. To test this possibility, we examined whether addition of purified CS to cultured keloid fibroblasts affects elastic fiber formation. In the absence of CS addition, keloid fibroblasts developed normal elastic fibers as analyzed by immunostaining of DANCE, fibrillin-1 (Fig. 3A), and elastin (Fig. 3B). 
These three proteins were deposited in a fine meshwork, and DANCE colocalized with fibrillin-1. In contrast, addition of purified CS to cultured keloid fibroblasts inhibited deposition of these three proteins. $\underline{\text { Similar }}$ effects were observed by using normal skin fibroblasts (data not shown). In the three subtypes of CS (CSA, CSB and CSC) examined, CSB most strongly blocked the deposition of elastic fiber components (Fig. 3A and 3B). CSA and CSC exhibited no significant difference in the efficiency to inhibit the deposition of elastic fiber proteins. The inhibitory effect was dose dependent (Supplementary Fig. 1). Treatment of keloid fibroblast culture with combination of two CS subtypes increased the inhibition efficiency, and the inhibition was most effective when CSB was included (Fig. 3A and 3B). The strongest interference was observed by the presence of the three subtypes. In contrast, HA had no significant effect on the elastic fiber formation (Fig. 3C), and increase concentration of HA did not affect elastogenesis (Supplementary Fig.2). These data indicate that CS can interfere with elastic fiber formation and that CSB is the most effective subtype. The inhibitory effect of CS may be exerted through inhibition of fibrillin-1 activity, as fibrillin-1 is reported to act as scaffolds and to direct the morphogenesis of elastic fibers.

Discussion

In the present study, we found that keloid lesions contain excess amounts 
of GAGs, particularly CS (6.9-fold higher than normal skin). Moreover, CS impaired normal elastic fiber formation when added to keloid fibroblast cultures. These results strongly suggest that excess amounts of CS may be responsible for the lack of elastic fiber formation in developing keloid lesions. This hypothsesis is consistent with previous observations that CS interfered with elastic fiber formation in congenital diseases, including fetal ductus arterious [23], Costello disease and Hurler disease [15], as well as in restenotic lesions after vascular injury [25]. In pathogenic cells in these diseases, CS exists as a side chain of versican, which is over-expressed in the lesions. Versican is a proteoglycan that is present in many types of connective tissues including those in blood vessels [26]. Overexpression of an artificial versican that lacks CS side chains (known as V3) in neointima after vascular injury leads to increased elastic fiber formation in the lesion [27]. These observations further support the hypothesis that CS has an inhibitory role in elastogenesis, although the molecular mechanism mediating this effect is not clear. We previously reported that versican expression was markedly up-regulated in keloid lesions [2]. The presence of excess versican is likely to be the major source of the CS accumulation in keloid lesions. In the present study, we found that CSA/C and CSB were increased 12.1-fold and 5.1-fold in keloids relative to normal skin, respectively. Since versican has $\mathrm{CSA} / \mathrm{C}$ and $\mathrm{CSB}$ side chains, the accumulation of $\mathrm{CSA} / \mathrm{C}$ and $\mathrm{CSB}$ may be due to the over-expression of versican. 
Elastic fiber formation is a multi-step process controlled by fibrillin-1, DANCE and other proteins, although the molecular mechanisms are largely unknown. In this process, fibrillin-1 acts as a template on which tropoelastin deposits [10]. Fibrillin-1 is crucial for elastic fiber formation and mutations in the fibrillin-1 gene cause Marfan syndrome, a hereditary connective tissues disease [28]. DANCE is also essential for elastogenesis because DANCE deficient mice show human aging-like phenotypes caused by disorganized elastic fibers $[12,13]$. Recombinant DANCE can induce elastic fiber formation, even in serum-free cell culture, suggesting that this protein may be an organizer of elastogenesis [14]. DANCE deposition on microfibrils is considered to promote coaservation and crosslinking of tropoelastin along microfibrils [14]. In the present study, we found that both of fibrillin-1 and DANCE deposition is strongly reduced in keloid lesions and in the extracellular matrix produced by cultured keloid fibroblasts after addition of purified CS. Taken together, these observations suggest that CS interferes with developing intact fibrillin-1 scaffold, resulted in inhibition of DANCE interactions with microfibrils in keloid lesions, finally tropoelastin couldn't deposit on microfibrils (Fig. 3C). In conclusion, our present results strongly suggest that excessive accumulation of CS mediate the loss of elastic fibers in keloid lesions through inhibition of microfibril template formation. The findings described in the present study contribute to a further understanding of the pathology of keloids and may lead to new therapies. 
Interestingly, Costa et al. reported that elastic fibers in keloids were recovered concomitantly with an improvement in the clinical appearance of the tissue after a pressure treatment [29], suggesting that keloid pathogenesis and clinical outcomes correlate well with matrix abnormalities. Treatments that reduce the excess CS may induce normal elastic fiber formation in the lesions, and could provide a novel therapy in the treatment of keloid. As shown in the present study, CSA/C and CSB excessively deposite in keloid lesions. Although CSB was the strongest inhibitor of elastic fiber formation, and CSA/C also had an inhibitory effect against elastogenesis. Thus, therapeutic approaches to reduce all three subtypes of CS (CSA, CSB and CSC) are probably required for the effective treatment of keloid, and enzyme that digests all CS subtypes (e.g., chondoitinase $\mathrm{ABC}$ ) may be useful to treat keloids. 
References

[1] P. J. Heenan, in Lever's Histopathology of the skin, 8th edition. (Elder, D., ed), pp847-887, Lippincott-Raven Publishers., Philadelphia. (1997).

[2] M. Naitoh, H. Kubota, M. Ikeda, T. Tanaka, H. Shirane, S. Suzuki, and K. Nagata, Gene expression in human keloids is altered from dermal to chondrocytic and osteogenic lineage. Genes Cells 10 (2005) 1081-1091.

[3] J. Peltonen, L.L. Hsiao, S. Jaakkola, S. Sollberg, M. Aumailley, R. Timpl, M.L. Chu, and J. Uitto, Activation of collagen gene expression in keloids: co-localization of type I and VI collagen and transforming growth factor-beta 1 mRNA. J Invest Dermatol 97 (1991) 240-248.

[4] M. Naitoh, N. Hosokawa, H. Kubota, T. Tanaka, H. Shirane, M. Sawada, Y. Nishimura, and K. Nagata, Upregulation of HSP47 and collagen type III in the dermal fibrotic disease, keloid. Biochem Biophys Res Commun 280 (2001) 1316-1322.

[5] K.R. Taylor, and R.L. Gallo, Glycosaminoglycans and their proteoglycans: host-associated molecular patterns for initiation and modulation of inflammation. Faseb J 20 (2006) 9-22.

[6] D.A. Swann, H.G. Garg, W. Jung, and H. Hermann, Studies on human scar tissue proteoglycans. J Invest Dermatol 84 (1985) 527-531. 
[7] K.S. Bhangoo, J.K. Quinlivan, and J.R. Connelly, Elastin fibers in scar tissue. Plast Reconstr Surg 57 (1976) 308-313.

[8] N.V. Kamath, A. Ormsby, W.F. Bergfeld, and N.S. House, A light microscopic and immunohistochemical evaluation of scars. J Cutan Pathol 29 (2002) 27-32.

[9] J. Rosenbloom, W.R. Abrams, and R. Mecham, Extracellular matrix 4: the elastic fiber. Faseb J 7 (1993) 1208-1218.

[10] C.M. Kielty, M.J. Sherratt, and C.A. Shuttleworth, Elastic fibres. J Cell Sci 115 (2002) 2817-2828.

[11] L. Carta, L. Pereira, E. Arteaga-Solis, S.Y. Lee-Arteaga, B. Lenart, B. Starcher, C.A. Merkel, M. Sukoyan, A. Kerkis, N. Hazeki, D.R. Keene, L.Y. Sakai, and F. Ramirez, Fibrillins 1 and 2 perform partially overlapping functions during aortic development. J Biol Chem 281 (2006) 8016-8023.

[12] T. Nakamura, P.R. Lozano, Y. Ikeda, Y. Iwanaga, A. Hinek, S. Minamisawa, C.F. Cheng, K. Kobuke, N. Dalton, Y. Takada, K. Tashiro, J. Ross Jr, T. Honjo, and K.R. Chien, Fibulin-5/DANCE is essential for elastogenesis in vivo. Nature 415 (2002) 171-175.

[13] H. Yanagisawa, E.C. Davis, B.C. Starcher, T. Ouchi, M. Yanagisawa, J.A. Richardson, and E.N. Olson, Fibulin-5 is an elastin-binding protein essential for elastic fibre development in vivo. Nature 415 (2002) 168-171. 
[14] M. Hirai, T. Ohbayashi, M. Horiguchi, K. Okawa, A. Hagiwara, K.R. Chien, T. Kita, and T. Nakamura, Fibulin-5/DANCE has an elastogenic organizer activity that is abrogated by proteolytic cleavage in vivo. J Cell Biol 176 (2007) 1061-1071.

[15] A. Hinek, K.R. Braun, K. Liu, Y. Wang, and T.N. Wight, Retrovirally mediated overexpression of versican $v 3$ reverses impaired elastogenesis and heightened proliferation exhibited by fibroblasts from Costello syndrome and Hurler disease patients. Am J Pathol 164 (2004) 119-131.

[16] R.P. Mecham, Modulation of elastin synthesis: in vitro models. Methods Enzymol 144 (1987) 232-246.

[17] M. Shinmei, S. Miyauchi, A. Machida, and K. Miyazaki, Quantitation of chondroitin 4-sulfate and chondroitin 6-sulfate in pathologic joint fluid. Arthritis Rheum 35 (1992) 1304-1308.

[18] H. Yamada, S. Miyauchi, M. Morita, Y. Yoshida, Y. Yoshihara, T. Kikuchi, O. Washimi, Y. Washimi, N. Terada, T. Seki, and K. Fujikawa, Content and sulfation pattern of keratan sulfate in hip osteoarthritis using high performance liquid chromatography. J Rheumatol 27 (2000) 1721-1724.

[19] I. Takazono, and Y. Tanaka, Quantitative analysis of hyaluronic acid by high-performance liquid chromatography of streptomyces hyaluronidase digests. J Chromatogr 288 (1984) 167-76. 
[20] E.F. Roark, D.R. Keene, C.C. Haudenschild, S. Godyna, C.D. Little, and W.S. Argraves, The association of human fibulin-1 with elastic fibers: an immunohistological, ultrastructural, and RNA study. J Histochem Cytochem 43 (1995) 401-411.

[21] M. Zanetti, P. Braghetta, P. Sabatelli, I. Mura, R. Doliana, A. Colombatti, D. Volpin, P. Bonaldo, and G.M. Bressan, EMILIN-1 deficiency induces elastogenesis and vascular cell defects. Mol Cell Biol 24 (2004) 638-650.

[22] S.A. Jensen, D.P. Reinhardt, M.A. Gibson, and A.S. Weiss, Protein interaction studies of MAGP-1 with tropoelastin and fibrillin-1. J Biol Chem 276 (2001) 39661-39666.

[23] A. Hinek, R.P. Mecham, F. Keeley, and M. Rabinovitch, Impaired elastin fiber assembly related to reduced $67-\mathrm{kD}$ elastin-binding protein in fetal lamb ductus arteriosus and in cultured aortic smooth muscle cells treated with chondroitin sulfate. J Clin Invest 88 (1991) 2083-2094.

[24] S. Tajima, and Y. Nagai, Distribution of macromolecular components in calf dermal connective tissue. Connect Tissue Res 7 (1980) $65-71$.

[25] R. Huang, M.J. Merrilees, K. Braun, B. Beaumont, J. Lemire, A.W. Clowes, A. Hinek, and T.N. Wight, Inhibition of versican synthesis by antisense alters smooth muscle cell phenotype and induces 
elastic fiber formation in vitro and in neointima after vessel injury. Circ Res 98 (2006) 370-377.

[26] T.N. Wight, Versican: a versatile extracellular matrix proteoglycan in cell biology. Curr Opin Cell Biol 14 (2002) 617-623.

[27] M.J. Merrilees, J.M. Lemire, J.W. Fischer, M.G. Kinsella, K.R. Braun, A.W. Clowes, and T.N. Wight, Retrovirally mediated overexpression of versican $\mathrm{v} 3$ by arterial smooth muscle cells induces tropoelastin synthesis and elastic fiber formation in vitro and in neointima after vascular injury. Circ Res 90 (2002) 481-487.

[28] H.C. Dietz, G.R. Cutting, R.E. Pyeritz, C.L. Maslen, L.Y. Sakai, G.M. Corson, E.G. Puffenberger, A. Hamosh, E.J. Nanthakumar, S.M. Curristin, G. Stetten, D.A. Meyers, C.A. Francomano. Marfan syndrome caused by a recurrent de novo missense mutation in the fibrillin gene. Nature. 352(1991) 337-339.

A.M. Costa, S. Peyrol, L.C. Porto, J.P. Comparin, J.L. Foyatier, and

[29] A. Desmouliere, Mechanical forces induce scar remodeling. Study in non-pressure-treated versus pressure-treated hypertrophic scars. Am J Pathol 155 (1999) 1671-1679. 
Figure Legends

Fig. 1. Analysis of elastic fiber components in keloid and normal skin tissues. (A, B) Immunostaining of elastic fiber components. Sections prepared from the keloid lesions and normal skin were stained with antibodies against elastin (A), DANCE and fibrillin-1 (B). Bar=40 $\mu \mathrm{m}$. (C) HE (upper panel) and Elastica Van-Gieson (lower panel) staining of the boundary region between keloid and normal skin tissues. k, keloid lesion; n, unaffected skin. Bar=500 $\mu \mathrm{m}$. (D) Analysis of mRNA levels of elastic fiber components. The indicated mRNAs from keloid and normal skin samples were analyzed by RT-PCR of total RNA.

Fig. 2. Analysis of GAGs accumulation in keloid lesions by Alcian Blue staining after enzymatic treatment and HPLC assay. (A) Sections of keloid lesions (a) and normal skin (b) were stained with Alcian Blue. Sections of keloid lesions were incubated with chondoroitinase ABC (c) or hyaruronidase (d) and then stained with Alcian Blue. (B) Analysis of CS, HA and KS content in normal skin and keloids by HPLC. Content of these GAGs pere mg dry weight of tissue is shown (mean $\pm \mathrm{SD} ; \mathrm{n}=6)$. (C) Analysis of CSA/C and CSB content in normal skin and keloids. Contents of these CS subtypes determined by HPLC analysis are shown (mean \pm $\mathrm{SD} ; \mathrm{n}=6)$. 
Fig. 3. Inhibition of elastic fiber formation by addition of purified CS and HA to keloid fibroblast culture. (A, B) Fibroblasts obtained from keloid tissues were cultured in the presence or absence of CS. Bar=50 $\mu \mathrm{m}$. The cell culture was then doubly stained with antibodies against DANCE and fibrllin-1 (A) or with antibody against elastin (B). Hoechst was used to stain nuclei. (C) Fibroblasts obtained from keloid tissues were cultured in the presence of HA and stained with antibodies against DANCE and fibrllin-1 (top), or with antibody against elastin (bottom). Bar=100 $\mu \mathrm{m}$. (D) A model for insufficient deposition of elastin fiber components in the keloid matrix. This model shows that microfibrils are a scaffold for the deposition of elastic fiber components. DANCE promotes fibrillar deposition and cross-linking of tropoelastins on microfibrils to develop elastic fibers in normal skin. In contrast, CS probably prevents formation of microfibril platform and thus inhibits recruitment of elastin to microfibrils by DANCE in keloid lesions. 
A

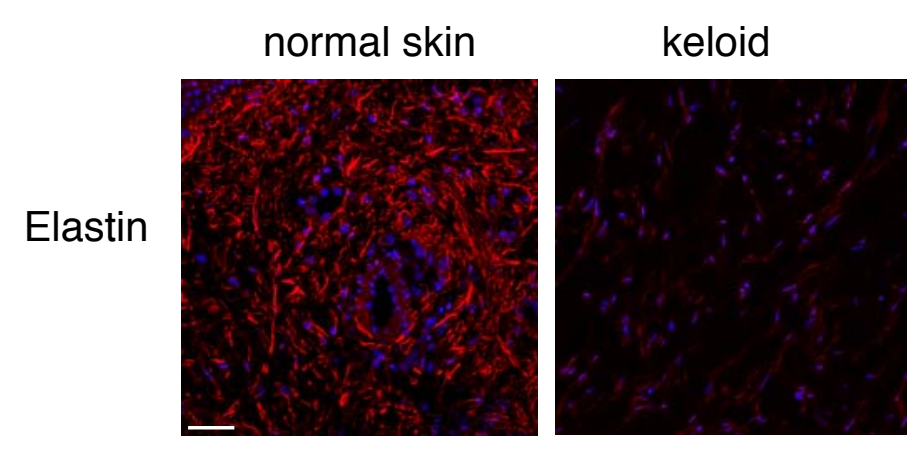

B

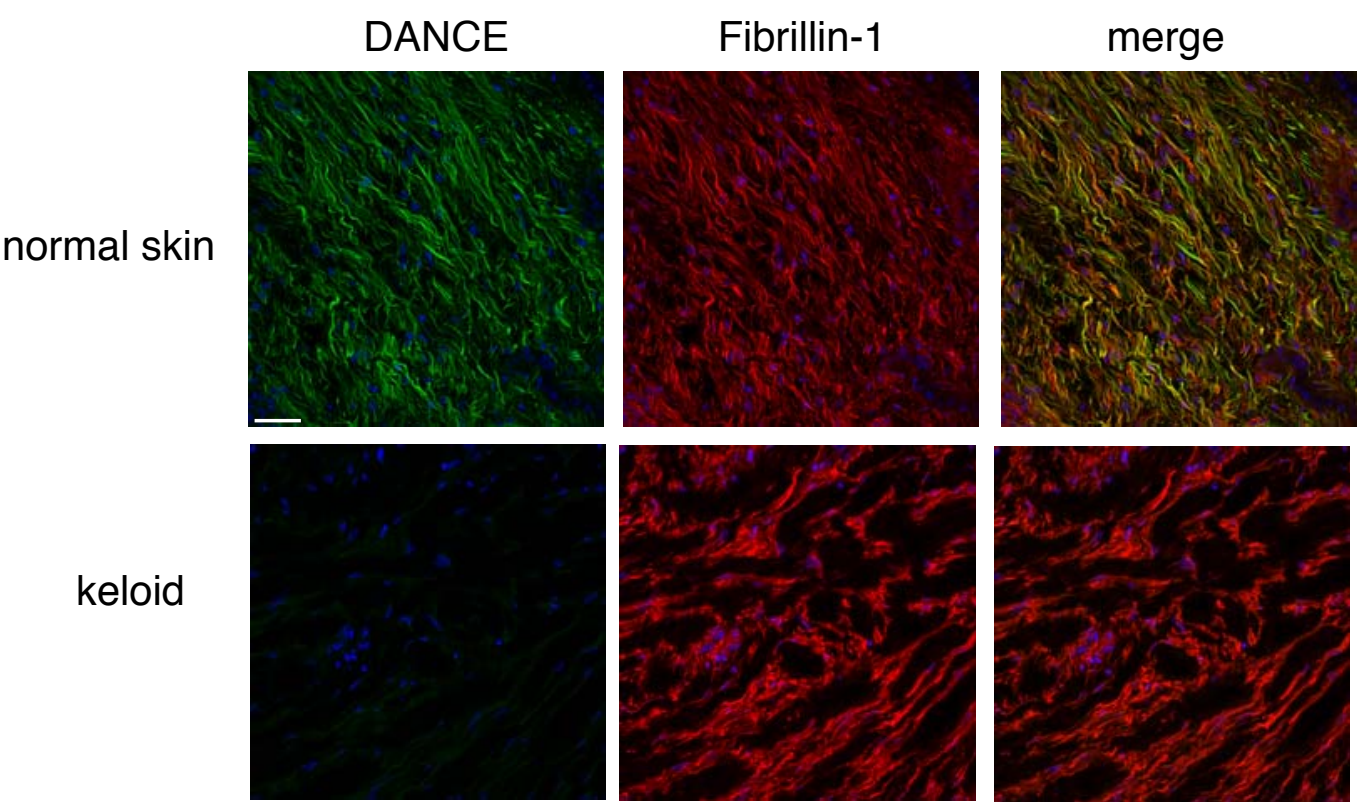

C

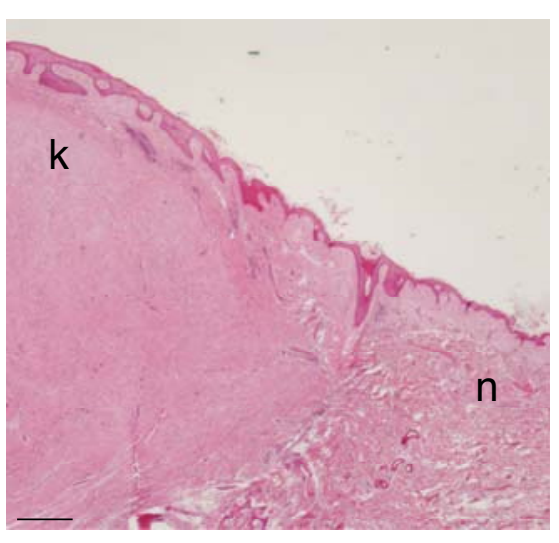

D

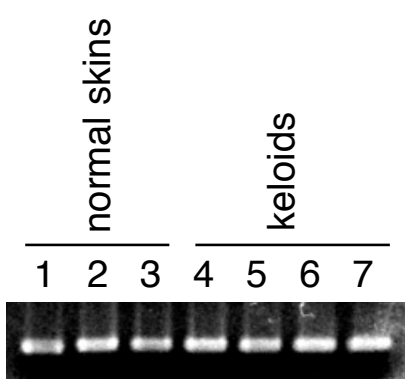

fibrillin-1

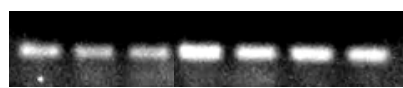

fibrillin-2
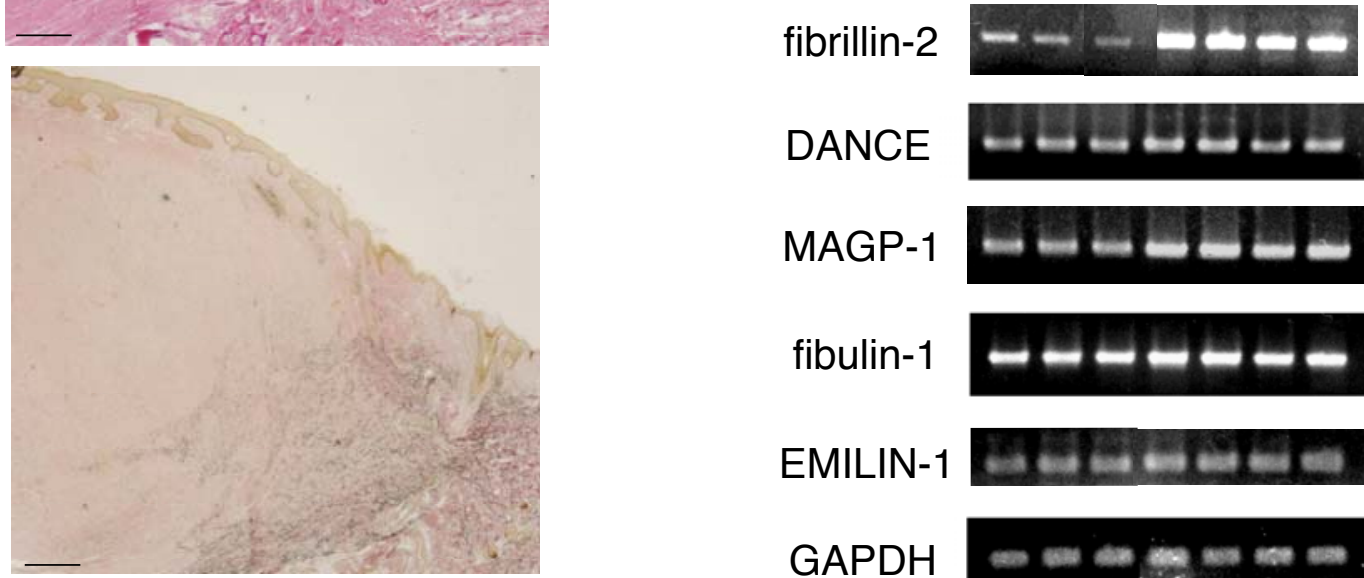

fibulin-1

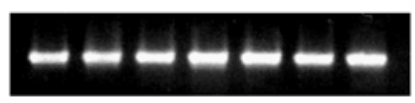

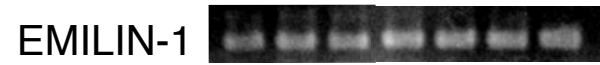

GAPDH

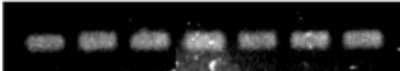

Fig. 1 
A
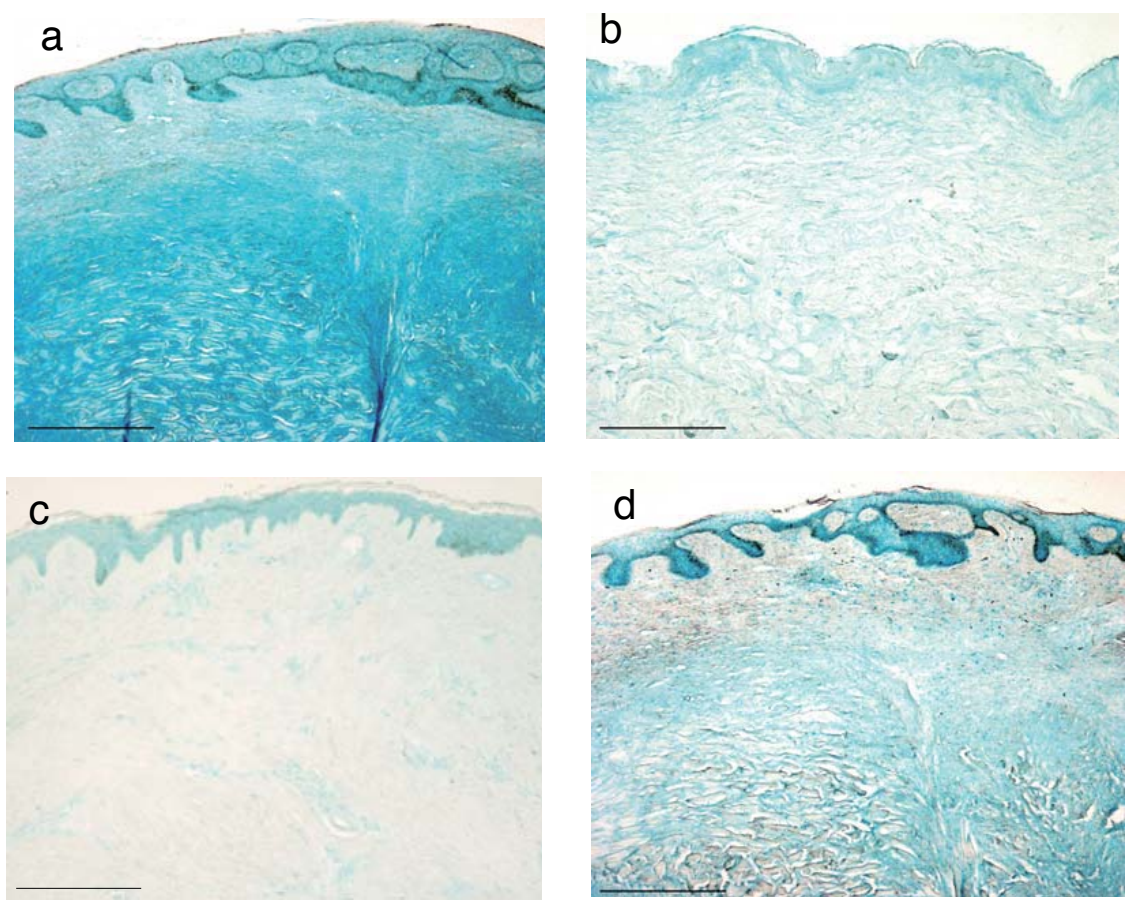

Bar ; $500 \mu m$

B
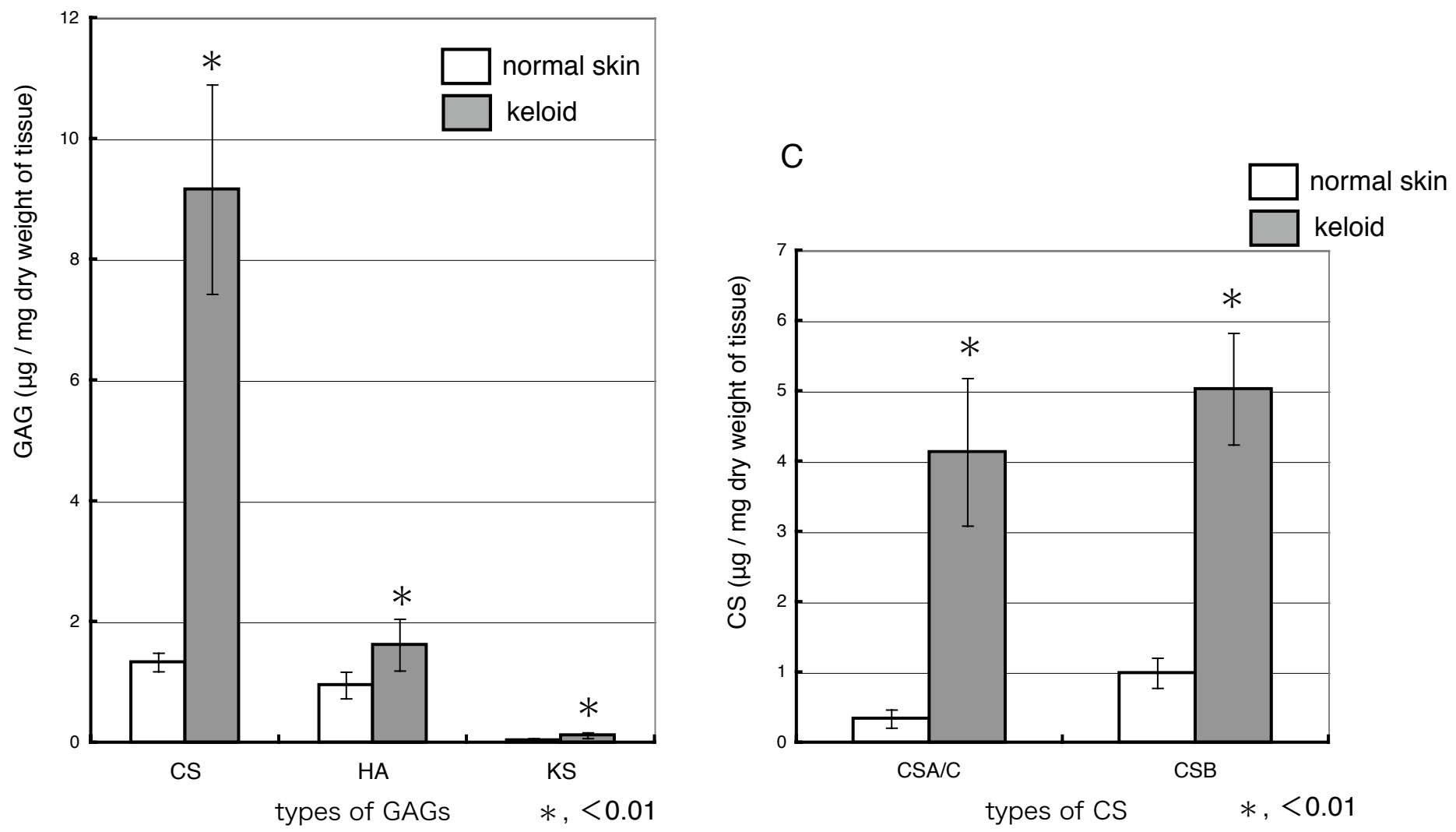

Fig. 2 
Hoechst

CS(-)

CSA

CSB

CSC

$\mathrm{CSA}+\mathrm{B}$

$\mathrm{CSA}+\mathrm{C}$

$\mathrm{CSB}+\mathrm{C}$

$\mathrm{CSA}+\mathrm{B}+\mathrm{C}$
Fibrillin-1
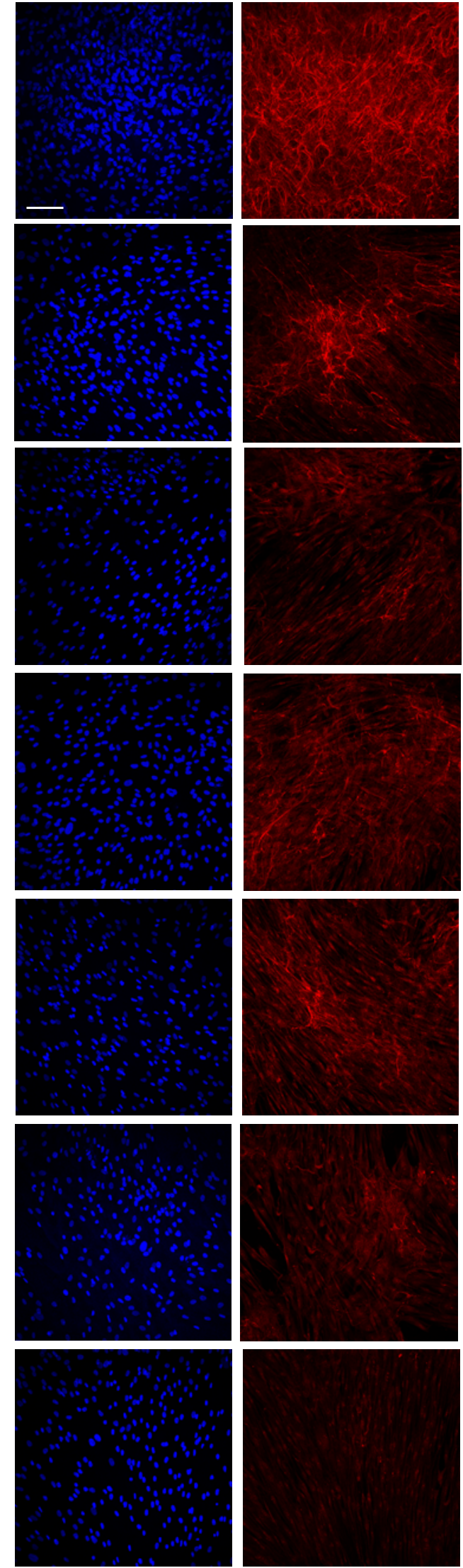

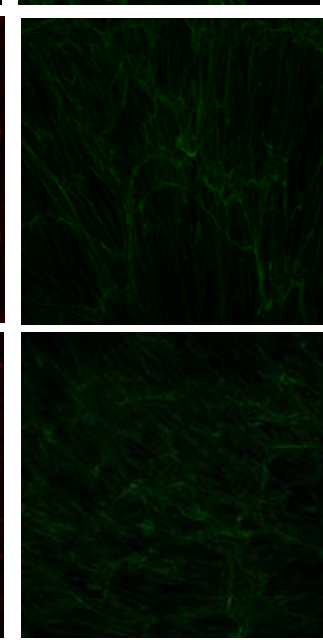

DANCE

Merge
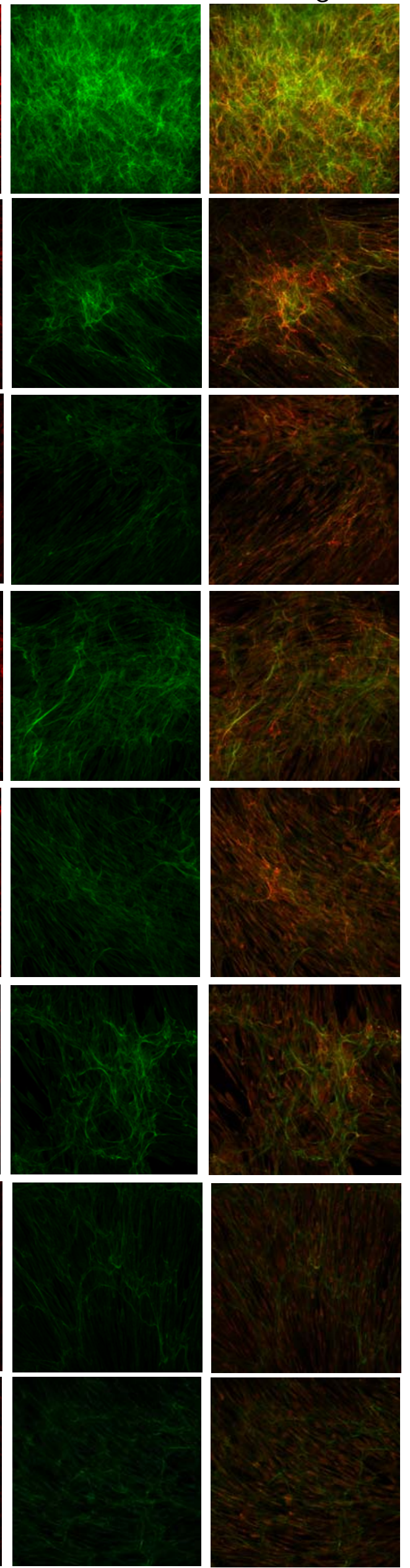

Fig. $3 \mathrm{~A}$ 

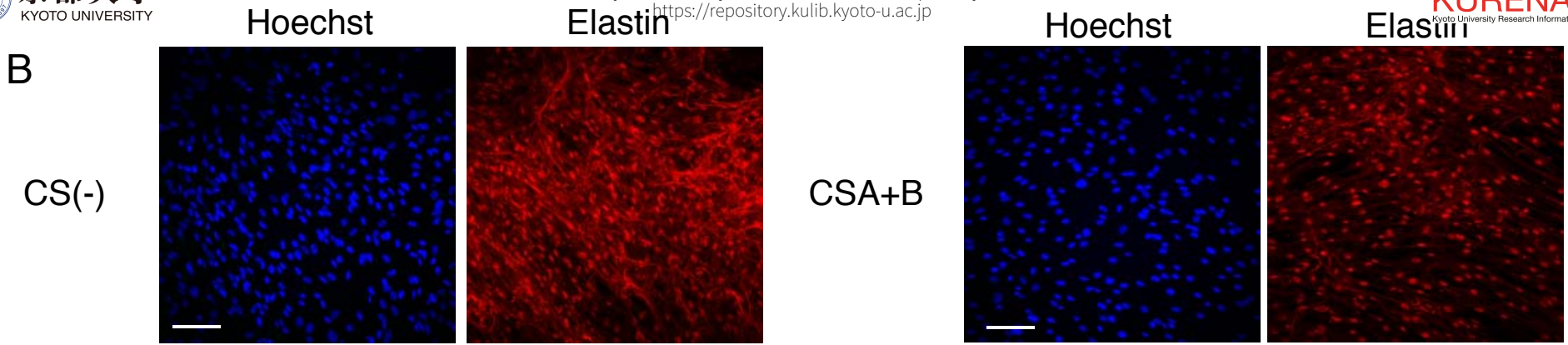

$\mathrm{CSA}+\mathrm{C}$

CSA
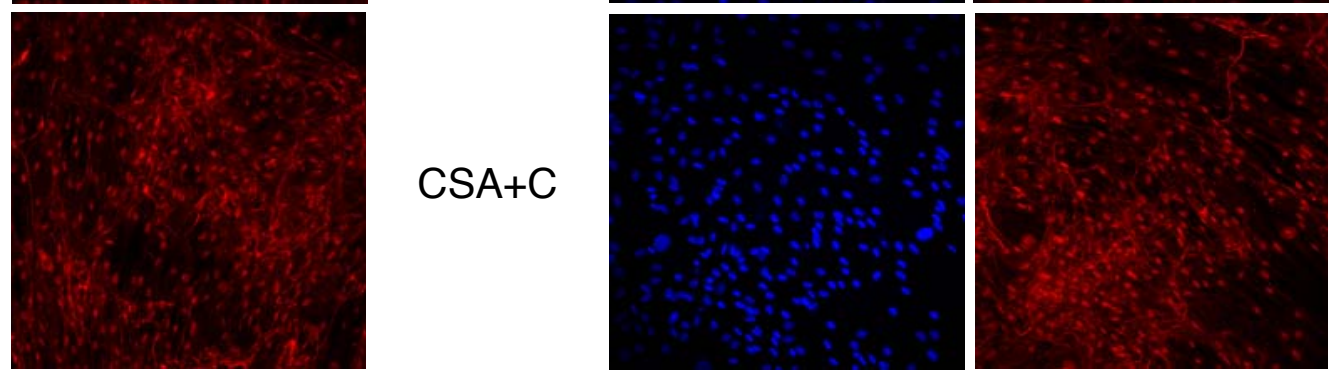

CSB

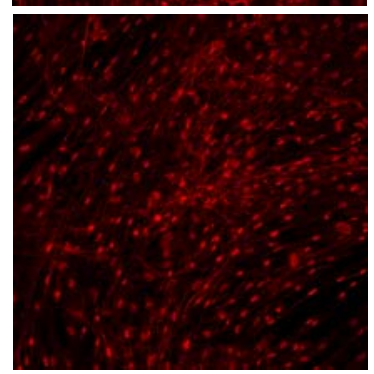

$\mathrm{CSB}+\mathrm{C}$

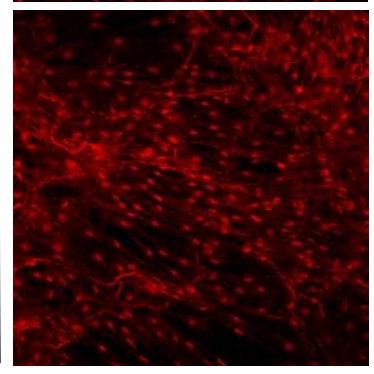

$\mathrm{CSA}+\mathrm{B}+\mathrm{C}$

CSC

Flbrillin-1

DANCE

C

Hoechst

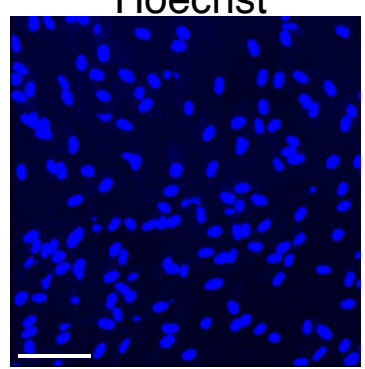

Hoechst
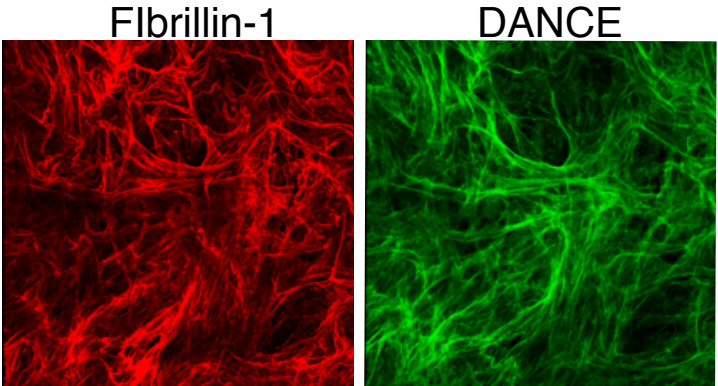

merge

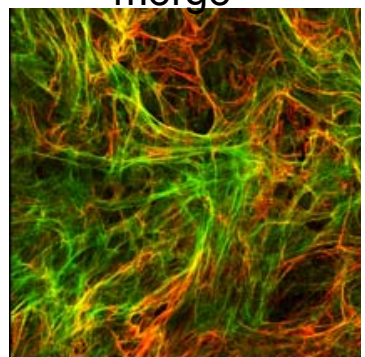

Elastin

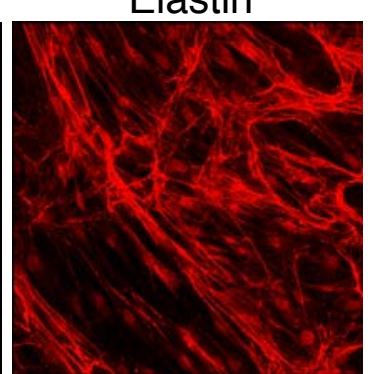

Fig.3

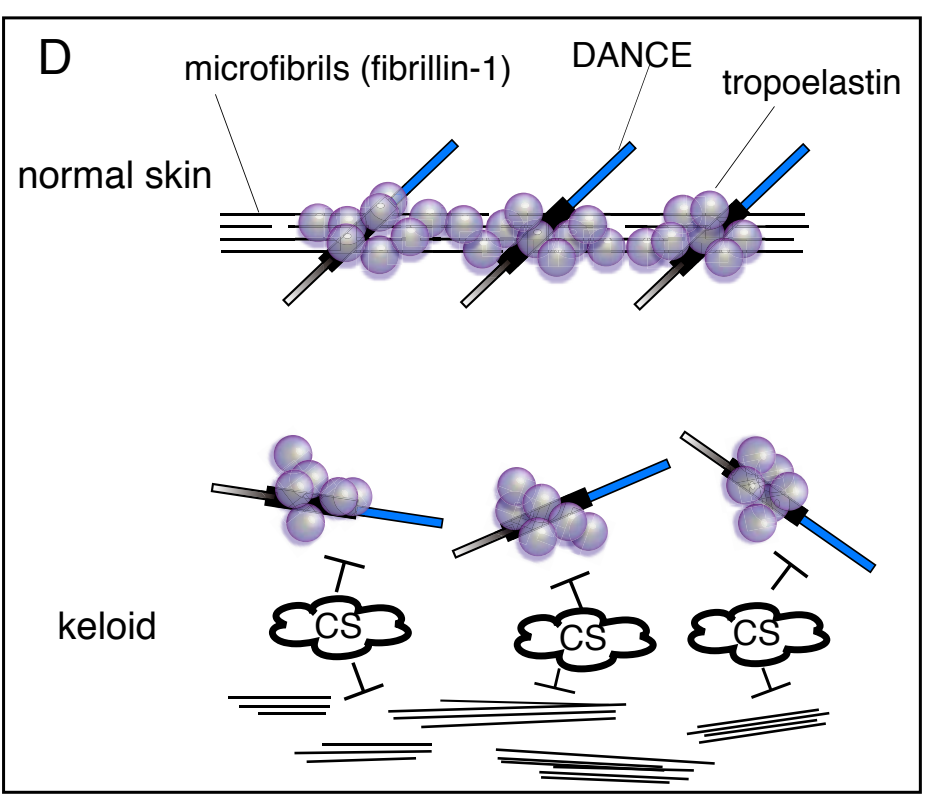


Table 1. GAGs in keloid and normal skin tissues quantified by HPLC.

\begin{tabular}{|c|c|c|c|c|c|c|c|}
\hline \multirow[t]{2}{*}{ tisuue } & \multirow[t]{2}{*}{ region } & \multirow[t]{2}{*}{ sex } & \multicolumn{3}{|c|}{$\mathrm{CS}(\mu \mathrm{g} / \mathrm{mg})$} & \multirow[t]{2}{*}{$\mathrm{HA}(\mu \mathrm{g} / \mathrm{mg})$} & \multirow[t]{2}{*}{$\mathrm{KS}(\mu \mathrm{g} / \mathrm{mg})$} \\
\hline & & & CSA/C & CSB & total & & \\
\hline keloid & chest & $\mathrm{F}$ & 3.56 & 5.16 & 8.72 & 1.56 & 0.11 \\
\hline keloid & chest & $M$ & 3.44 & 4.61 & 8.05 & 2.33 & 0.12 \\
\hline keloid & back & $M$ & 6.14 & 5.97 & 12.11 & 1.55 & 0.13 \\
\hline keloid & chest & $M$ & 3.31 & 3.81 & 7.12 & 1.87 & 0.08 \\
\hline keloid & ear & $F$ & 4.21 & 5.78 & 9.99 & 1.29 & 0.20 \\
\hline keloid & neck & $M$ & 4.11 & 4.87 & 8.98 & 1.12 & 0.06 \\
\hline normal skin & chest & $M$ & 0.25 & 0.96 & 1.21 & 0.98 & 0.02 \\
\hline normal skin & abdomen & $F$ & 0.32 & 0.92 & 1.24 & 1.28 & 0.03 \\
\hline normal skin & abcomrn & $F$ & 0.23 & 1.36 & 1.59 & 1.05 & 0.00 \\
\hline normal skin & abdomen & $M$ & 0.23 & 1.05 & 1.28 & 0.69 & 0.01 \\
\hline normal skin & back & $M$ & 0.51 & 0.92 & 1.43 & 0.99 & 0.12 \\
\hline normal skin & back & $M$ & 0.49 & 0.71 & 1.20 & 0.73 & 0.05 \\
\hline
\end{tabular}


Supplemental Table 1. List of all tissue samples used in this study

\begin{tabular}{|c|c|c|c|c|c|}
\hline No. & tissue & region & sex & age & assays \\
\hline 1 & normal skin & abdomen & $F$ & 23 & $A$ \\
\hline 2 & normal skin & abdomen & $\mathrm{F}$ & 22 & $A$ \\
\hline 3 & normal skin & neck & $M$ & 22 & $A$ \\
\hline 4 & normal skin & abdomen & $M$ & 69 & $B$ \\
\hline 5 & normal skin & thigh & $M$ & 57 & $B$ \\
\hline 6 & normal skin & chest & $M$ & 33 & $\mathrm{D}$ \\
\hline 7 & normal skin & abdomen & $\mathrm{F}$ & 14 & $\mathrm{D}$ \\
\hline 8 & normal skin & abdomen ${ }^{\#}$ & $M$ & 51 & $\mathrm{D}$ \\
\hline 9 & normal skin & abdomen ${ }^{\#}$ & $M$ & 48 & $\mathrm{D}$ \\
\hline 10 & normal skin & chest $^{\# \#}$ & $\mathrm{~F}$ & 39 & $\mathrm{D}$ \\
\hline 11 & normal skin & back $^{\#}$ & $M$ & 75 & $\mathrm{D}$ \\
\hline 12 & keloid & sholder & $\mathrm{F}$ & 21 & $A$ \\
\hline 13 & keloid & chest & $M$ & 37 & $A$ \\
\hline 14 & keloid & sholder & $M$ & 60 & $A$ \\
\hline 15 & keloid & chest & $M$ & 27 & $A$ \\
\hline 16 & keloid & chest & $\mathrm{F}$ & 19 & $B$ \\
\hline 17 & keloid & chest & $M$ & 67 & $B$ \\
\hline 18 & keloid & abdomen & $M$ & 58 & $B$ \\
\hline 19 & keloid & back & $\mathrm{F}$ & 19 & $\mathrm{C}$ \\
\hline 20 & keloid & chest & $M$ & 31 & C \\
\hline 21 & keloid & chest & $F$ & 39 & $D$ \\
\hline 22 & keloid & cehst & $M$ & 11 & $D$ \\
\hline 23 & keloid & back & $M$ & 37 & $D$ \\
\hline 24 & keloid & chest & $M$ & 36 & $D$ \\
\hline 25 & keloid & ear & $F$ & 20 & $D$ \\
\hline 26 & keloid & neck & $M$ & 48 & $\mathrm{D}$ \\
\hline
\end{tabular}

\#Unaffected skins apart from the leisons obtained from keloid patients.

\#\#naffected skin surrounding the keloid lesion. Assays to which the samples were subjected. A, RT-PCR; B, Alcian blue staining; C, in vitro elastogenesis assay; D, GAG quantification by HPLC. 


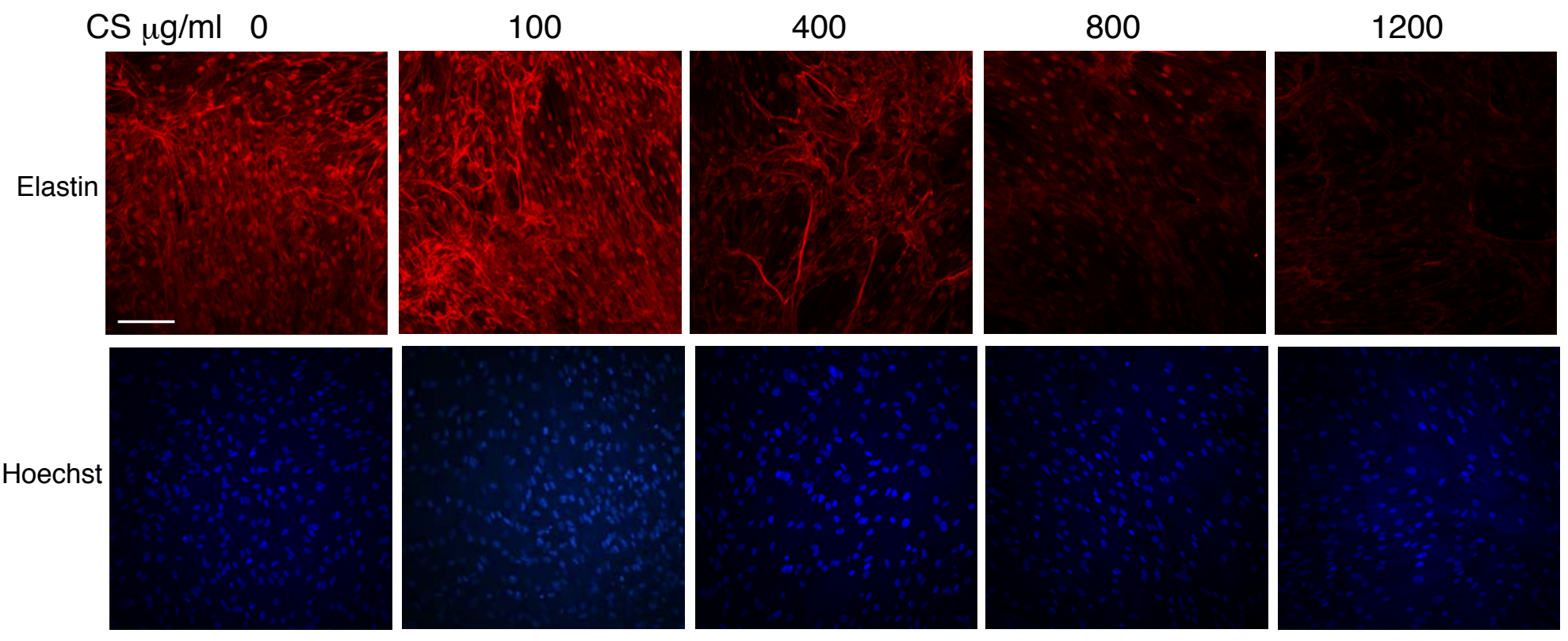

CS $\mu \mathrm{g} / \mathrm{ml} \quad 0$

merge

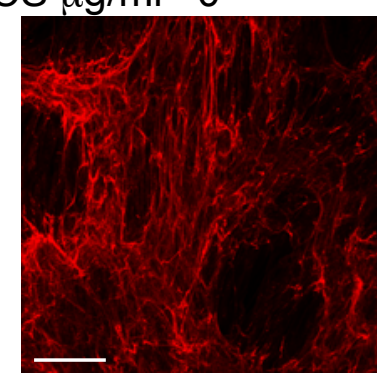

DANCE

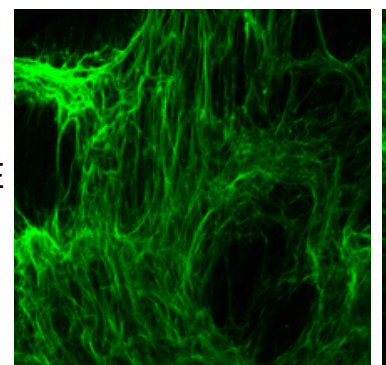

Hoechst
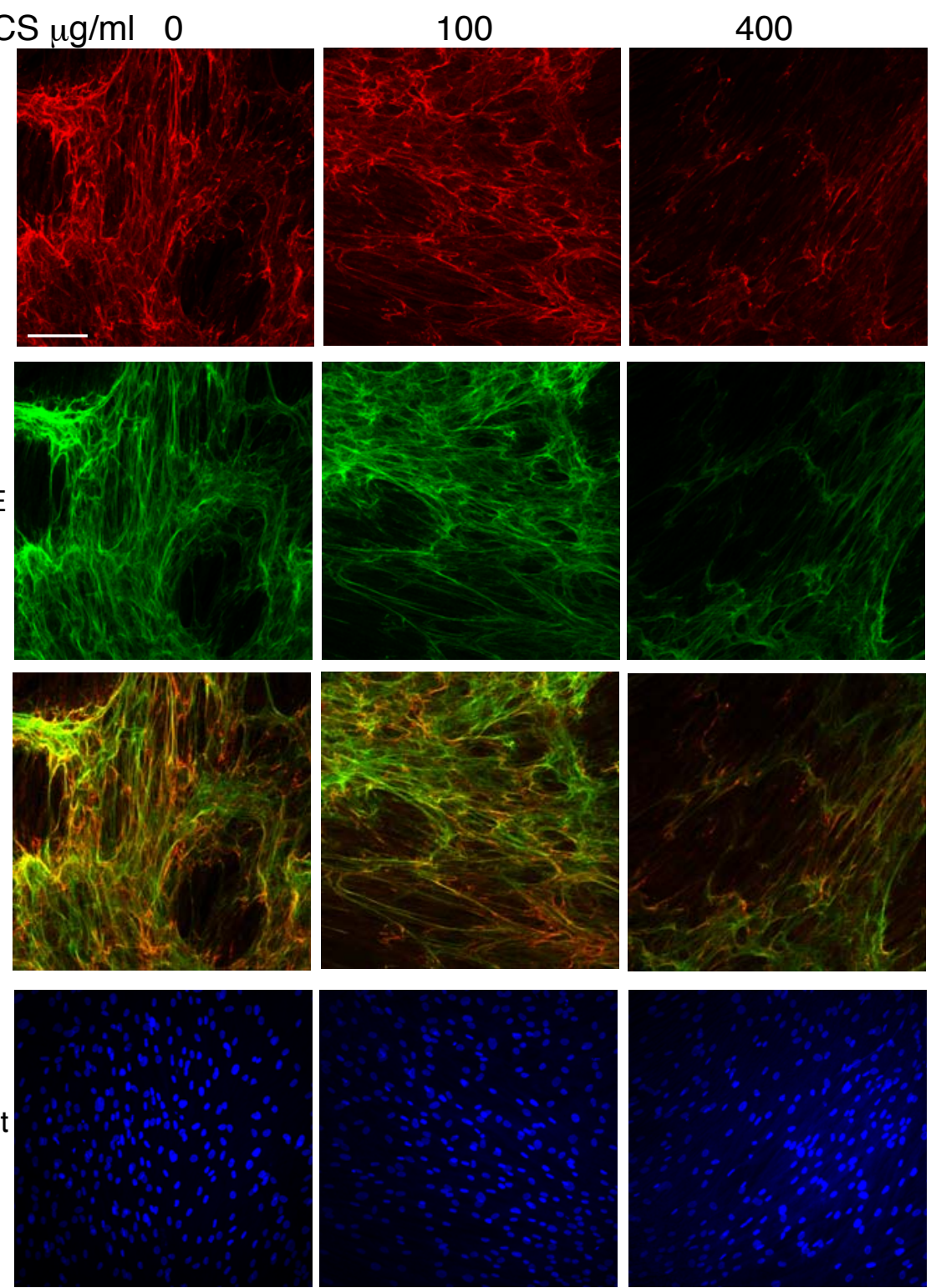
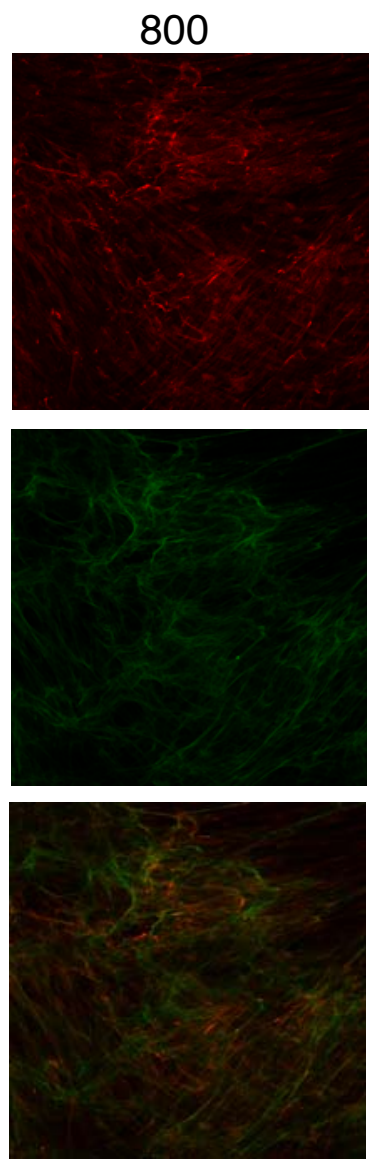

1200
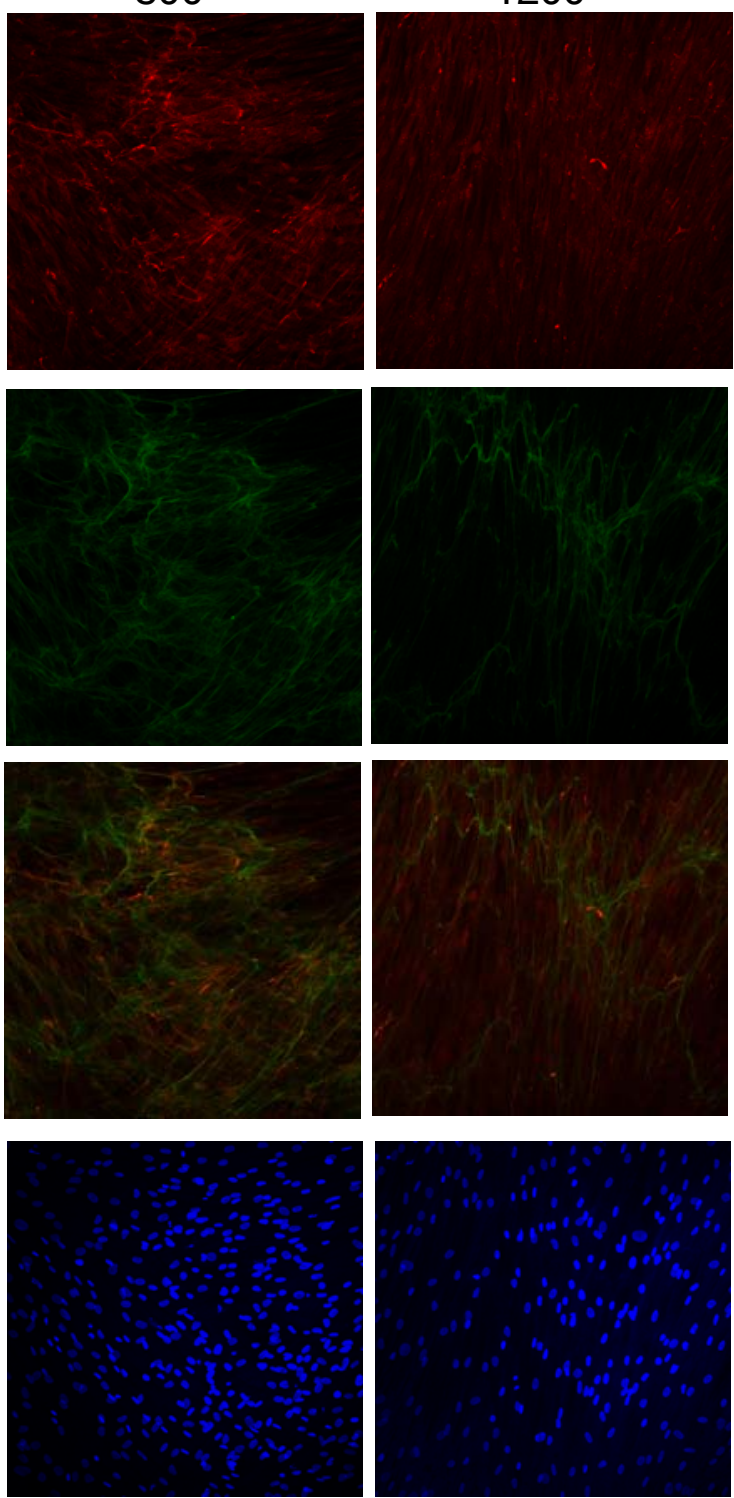
(2.) 京都大学

A Self-archived copy in
Kyoto University Research Information Repository

KURENAII 就

$\mathrm{HA} \mu \mathrm{g} / \mathrm{ml} \quad 0$

100

400

800

1200

Elastin
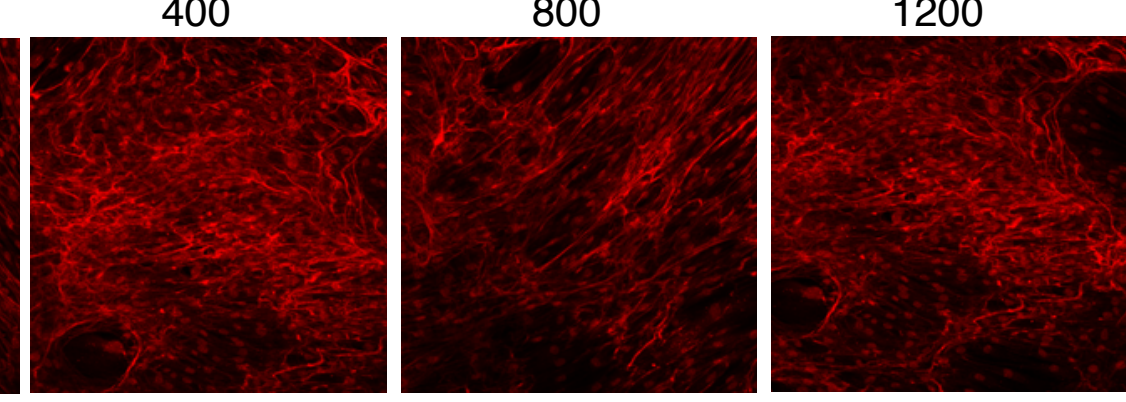

Hoechst

$\mathrm{HA} \mu \mathrm{g} / \mathrm{ml} \quad 0$

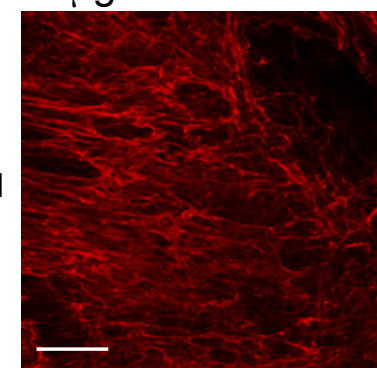

DANCE

merge
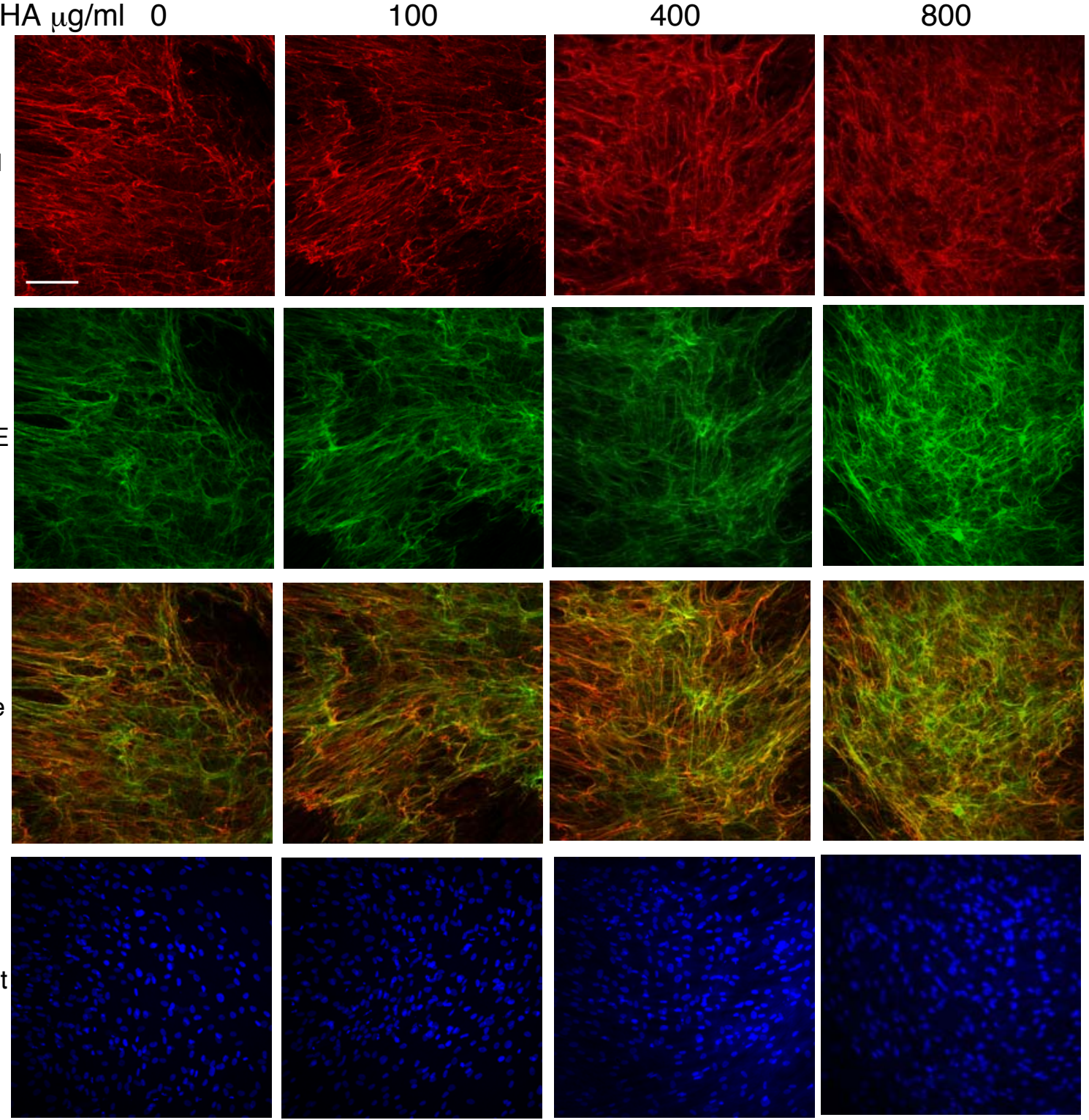

Hoechst

1200
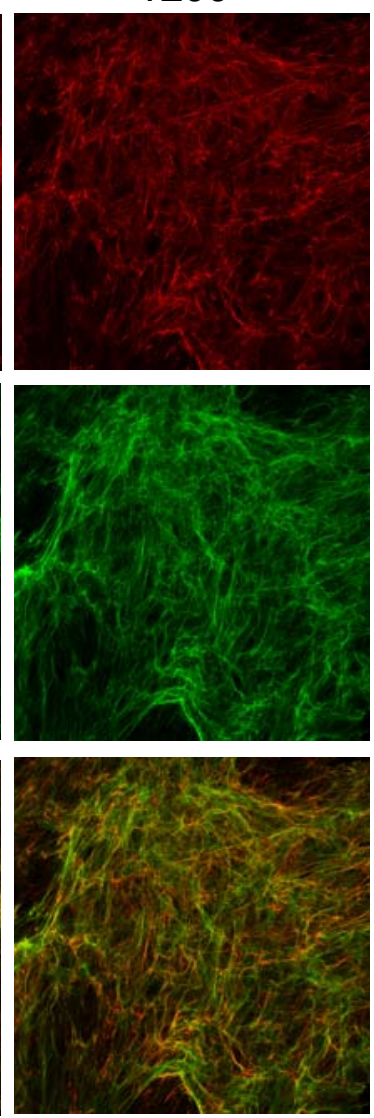

Suppl. Fig.2 
Supplementary figure legends

Supplementary Fig. 1. A combination of three subtypes of CS inhibits the deposition of fibrillin-1, DANCE and elastin in extra cellular matrix by cultured keloid fibroblasts in a dose-dependent manner. Keloid fibroblasts were cultured in the presence of CSA+CSB+CSC $(100,400,800$ or 1200 $\mu \mathrm{g} / \mathrm{ml}$ ), or the absence of CS as a control. Cultured cells were fixed and stained with an antibody against elastin or antibodies against fibrllin-1 and DANCE. Counter staining by Hoechst was performed to visualize nuclei. Bar $=100 \mu \mathrm{m}$.

Supplementary Fig. 2. Addition of purified HA has no significant effect on elastic fibers formation by cultured keloid fibroblast. Furthermore, HA did not affect elastogenasis even though its concentration was increased. Keloid fibroblasts were cultured in the presence of 100, 400, 800 or 1200 $\mu \mathrm{g} / \mathrm{ml} \mathrm{HA}$, or the absence of HA. Cultured cells were fixed and doubly stained with an antibody against elastin or antibodies against fibrllin-1 and DANCE. Counter staining by Hoechst was performed. Bar $=100 \mu \mathrm{m}$. 